\title{
Accessibility of Websites of the European National Tourism Boards
}

Submitted 11/02/20, 1st revision 28/02/19, 2nd revision 19/03/20, accepted 04/04/20

Filip Rubáček ${ }^{1}$, Irena Jindřichovská ${ }^{2}$, Zuzana Horváthová3 ${ }^{3}$ Josef Abrhám ${ }^{4}$

\begin{abstract}
:
Purpose: The aim is to find out the current state of accessibility of the websites of European national tourism boards. Furthermore, the identification of the most common errors in terms of accessibility as well as recommendations leading to their correction is aimed for.

Design/methodology/approach: The study is based on methods of testing the availability of web systems. The testing included automated tools, namely AChecker and Accessibility Evaluation Tool, as well as the WCAG 2.1 checklist developed by WebAIM initiative.

Findings: The research has shown a relatively high accessibility of those websites. Nevertheless, some accessibility violations have been identified that can significantly complicate the accessibility of those websites for users using various assistive devices or other alternative hardware or software means. The most commonly identified errors include: failure to use alternative text for content-relevant images, the absence of text or audio transcripts for videos shared via Youtube, missing descriptions for text form elements and missing label for search form.

Practical implications: The results of the research can be used in the evaluation of web presentations at the level of tourism boards and destination management.

Originality/Value: The main output of this article is the application of web testing methodology on a comprehensive set of national tourist boards.
\end{abstract}

Keywords: Tourism, accessibility, websites, national tourism board.

JEL codes: Z3, Z32, L84.

Paper Type: Research article.

Acknowledgments: This paper is the result of Metropolitan University Prague research project no. 74-02 "Territorial Studies, Economics, International Relations" (2019) based on a grant from the Institutional Fund for the Long-term Strategic Development of Research Organisations.

\footnotetext{
${ }^{l}$ Ph.D., Department of Tourism. Metropolitan University Prague, E-mail: filip.rubacek@mup.cz

${ }^{2}$ Doc. Ing. CSc., Department of International Business. Metropolitan University Prague, Email: irena.jindrichovska@mup.cz

${ }^{3}$ Ph.D., Department of Legal Specialisations and Public Administration. Metropolitan University Prague, E-mail: zuzana.horvathova@mup.cz

${ }^{4}$ Ph.D., Department of Tourism. Metropolitan University Prague, E-mail: josef.abrham@mup.cz
} 


\section{Introduction}

This paper is involved with the accessibility of tourism for people with specific needs. Accessible tourism represents not only socially responsible, but also a promising industrial branch (Cech, Jindřichovská and Neubauer, 2018 and 2019). There are currently more than 150 million people in Europe with specific needs (especially seniors and people with disabilities). The number of these persons is gradually increasing. By 2030, the market potential of accessible tourism should include nearly a third of the population (European Commission, 2015). It is therefore a significant market segment from the perspective of tourism service providers. An increase in demand and an increase in the number of jobs in the area can be expected in the future (Srimuk and Choibamroong, 2014; Goryushkina et al., 2019).

Accessibility in tourism includes the infrastructure of accommodation facilities, barrier-free transport, specialized services of travel agencies and processions, management of accessible destinations, etc., (Sirotková et al., 2018). In addition to physical accessibility, other forms of accessibility such as economic, social, psychological, and informational and the like have been defined. The online market is gaining in importance as information accessibility of tourism (Bondarenko et al., 2019; Abrhám and Lžičař, 2018). Clients with specific needs should be able to obtain detailed and understandable information. Information sources should be adapted to the specific needs of individual groups in terms of readability e.g. containing audio recordings, etc. In this context, methods for testing and validating information technology in tourism were designed (Abrhám and Wang, 2017).

The issue of quality of websites is a heavily discussed topic in many areas of software engineering accompanied with many different aspects and viewpoints. This feature must be firmly embedded in the PMS used in particular tourist resort or hotel chain Jindrichovska and Kohout (2016a and 2016b). Accessibility is certainly one of the key quality factors of those websites. Therefore, legal definition of accessibility of websites of both public sector bodies as well as state administration has been seeking for a solution for many years in all developed countries worldwide. In the EU, a Directive on the accessibility of the websites and mobile applications of public sector bodies is currently the basic norm (European Parliament, 2016). This directive has been gradually implemented in the national norms of EU member states. It can be assumed that national norms in the form of regulations will also include national tourism boards. Nevertheless, tourism websites should be as accessible as possible regardless of the norm and also, the websites of national tourism boards should serve as an example, because those are, especially for foreign tourists, often the first introduction to travel opportunities in Member States.

The aim of the paper is to find out the current state of accessibility of the websites of European national tourism boards. Furthermore, the identification of the most common errors in terms of accessibility as well as recommendations leading to their correction is aimed for. The study is based on methods of testing the availability of 
web systems. The testing included automated tools, namely AChecker and Accessibility Evaluation Tool, as well as the WCAG 2.1 checklist developed by WebAIM initiative.

\section{Literature Review}

The concept of accessibility of websites can be defined differently. The most wellknown website accessibility organization is the W3C Web Accessibility Initiative (WAI) operating within the World Wide Web Consortium (W3Chttps://www.w3.org/). The WAI defines the Web Content Accessibility Guidelines (WCAG), which consists of verifiable rules that should, when obeyed, ensure the accessible of websites (Kirkpatrick et al., 2018). The initiative is an internationally well recognized authority in the field of accessibility of web systems so that the terms, principles or even complete WCAGs are commonly used to define or verify the accessibility. Even the documents provided by the European Union institutions and bodies often work with the concepts and rules defined by the WAI. The EU directive defines four main principles of accessibility in the same way as WCAG do, and as an example for the verifiability of accessibility criteria, it names the European Standard EN 301 549, which refers directly to WCAG (European Parliament, 2016).

The WCAG 2.1 is a comprehensive and integral standard. It is a list of broadly conceived 78 guidelines divided into four basic principles according to which, the content must be perceptible, operable, understandable and robust. The guidelines are further divided into three levels (A, AA, AAA), where the levels determine the significance of the guidelines. A stands for the minimum level, AA represents the middle level and AAA means the highest level of the accessibility. The standard is intended not only for testing websites, but can be also used for testing other software tools. The definition of accessibility by this WAI is as follows: "Accessibility involves a wide range of disabilities, including visual, auditory, physical, speech, cognitive, language, learning, and neurological disabilities" (Caldwell et al., 2008).

In some professional publications, the concept of accessibility of websites may be broader than the one defined by the WIA. The accessibility is also linked to find ability. The criteria from the previous definitions are also added here, for example, by a Page rank or URL address of the website (Kopáčková et al., 2010), Some authors strive, within the broader concept of accessibility, for an effort to incorporate either the usability or the intersection of those terms (Vanderdonckt et al., 2004; Campbell, 2009). With regard to websites in tourism, both the usability and accessibility of websites are deemed crucial. We even believe that accessibility and usability define a quality websites in tourism. In this paper, however, we will focus only on the accessibility of the websites according to the traditional definition given by Rubacek (2011) "A well accessible website can be used by any users no matter what medical or technical limitations they might have”. 
Several tools for testing accessibility of web portals can be found in the literature. Web accessibility methods are divided into five categories: conformance review, automated testing, subjective assessment, screening techniques and user testing (Brajnik et al., 2010). The methods 3-5 are not suitable for quantitative research, especially due to a very difficult repeatability. Therefore, those methods are mainly used for qualitative research of a particular website.

For a quantitative or routine verification of the accessibility the most suitable method is Automated testing, possibly using Conformance review. The Conformance review method generally consists of evaluating a website according to predefined checkpoints. The need to use checkpoints is a weak point not only in the Conformance review method, but also in the Automated testing method, where testing is also limited to specific problems and not to a general principle. A website controlled by checkpoints may comply with given rules, though it may still be difficult to access. Without any checkpoints, however, a fast and routine method of verifying the accessibility of web systems cannot be applied. Although all common standards or checklists were created with the utmost consideration to minimize these risks, it is necessary to allow for this type of error in this area.

Although the Web Content Accessibility Guidelines (WCAG) is a kind of the concept that is directly defined by a list of rules, due to the complexity and generality of some of those rules, the checklists have also been developed for this standard. Under the umbrella of the Web Accessibility in Mind (WebAIM) organization, the most widely used simplified checklist of WCAG was created (WebAIM, 2019). The main purpose of the checklist is to present the principles of the WCAG standard in a more understandable way as well as to specify them for the web environment. All the checklist points copy the WCAG rules. The Conformance review method can be better applied to this list because of a greater simplicity.

As long as the application of accessibility testing of web presentations is concerned, studies focused on tourist centres have not been published in scientific literature. However, a number of studies are available to address the accessibility of web portals of public administration institutions in general (Akgül and Vatansever, 2016; Craven and Nietzio, 2007; Latif and Masrek, 2010; Goodwin et al., 2011; Hong et al., 2008; Isa et al., 2011; Basdekis et al., 2009; Al Mourad and Kamoun, 2013). For all these studies it is common to analyse the accessibility of web portals through quantitative methods. Automated testing was usually focused on selected checkpoints and accessibility standards. Here, the automatic testing tools WAVe, AChecker, eXaminator, Total Validator, and other engines were used. In particular, the researches were based on United Nations methodological regulations as well as on national standards. In terms of standards of professional organizations, the concepts of the World Wide Web consortium prevailed. The results of the studies have shown that most websites rated by public authorities do not show a sufficient level of website availability. However, the results of studies and the institutions involved differed according to the instruments analysed. Some web portals achieved 
better scores in terms of completeness others in terms of correctness. In summary, better results in terms of accessibility of web portals have been reported in most countries in developed countries than in developing countries (Goodwin et al., 2011; Katrakilidis et al., 2017).

\section{Research Methodology}

For testing, a modified methodology based on published research was used (Rubáček, 2011; Brajnik, 2008; Brajnik et al., 2010; Basdekis et al., 2009). The testing included automated tools, namely AChecker (AChecker) and Accessibility Evaluation Tool (WAVE), as well as the WCAG 2.1 checklist developed by WebAIM initiative (WebAIM). The very basic and necessary condition for both the repeatability and possible quantitative use of this methodology is testing by a tester with the knowledge of websites creation and their accessibility (Connor, 2010).

The web accessibility research was carried out in October 2019. All 27 websites of the European national tourism boards listed on the Official Travel Portal of Europe (ETC) were tested. The testing was performed by the authors of the paper. For each headquarters, two pages were tested, always a home page and a randomly selected page accessible via a link from the home page. The methodology used to test the accessibility of chosen websites is as follows (Rubáček, 2017):

1. Each page is ranked according to all $78 \mathrm{WCAG} 2.1$ criteria.

2. The page is first tested by AChecker and WAVE tools. The errors found are verified by manual code inspection. If the error found does not really meet the WCAG rule, then the score is 0 for that point.

3. All non-zero checkpoints are tested according to WCAG 2.1 checklist created by WebAIM initiative. In that list, each checkpoint is rated either by fulfilled (value 1) or failed (value 0) tags.

4. Should there be no test object or the property evaluated by a particular test criterion within the website, the point is considered fulfilled, because for example the absence of audio or the inability to store data over the website does not affect the accessibility of the page alone.

5. If the page contains anything contrary to the checkpoint, that checkpoint is considered not to be met. Otherwise it is assessed as fulfilled.

6. Complete results are immediately recorded.

The method does not determine the degree of (none) fulfilment of the checkpoint (the method does not address how often or how significantly the checkpoint was broken on the page), but it checks only whether the checkpoint is broken or not.

\section{Results and Recommended Solutions}

Standard statistical methods were used to process the results. First, basic descriptive characteristics for individual websites were calculated and a percentage rating of all 
78 WCAG criteria 2.1 were used. No rating made $100 \%$, but the results achieved a percentage criterion of from $88 \%$ to $99 \%$ per cent (Figure 1). The average rating is $94 \%$ with a coefficient of variation of 0.029 , a coefficient of skewness of -0.107 and a coefficient of sharpness of -0.793 . Therefore, the variability of the results is minimal.

This result can be considered very satisfactory, given both the complexity of the rules and the use of modern technologies on the websites of national tourism boards. However, it should be noted that for each boards only two pages were tested by the quantitative method and not completely the entire website. If we would thoroughly qualitatively test all the pages of the websites, the results would certainly be a little bit worse. For this reason, we also do not compare the results of individual boards in the ranking, because the results are very similar, the differences are statistically insignificant and in a more complex testing the ranking could change.

The basic descriptive characteristics were also used after comparing the individual WCAG 2.1 assessment criteria. The variability was higher here, namely the variation coefficient was 0.148 , the coefficient of skewness made -2.624 and the coefficient sharpness was 7.083 at an average score of 31.05 at $n=33$. The results show that both the variability and deviation of individual points from the Gaussian curve is great and the results are more interesting from the research point of view.

The results of the testing show that websites of national tourism boards in the EU are in principle relatively well accessible, but there are some problematic criteria in all four areas defined by the WAI initiative (Figure 2). The critical points will be analysed in more detail. The worst-ranked criterion of the EU tourism boards websites is criterion 1.1.1 (Non-text Content). This state: "All non-text content that is presented to the user has a text alternative that serves the equivalent purpose, except for the situations listed below" (Kirkpatrick et al., 2018). Only 10 out of the 33 websites tested met this criterion, and the vast majority of websites that did not meet this criterion have identified a problem of not using an alternative text for content-relevant images. It was never a kind of system error, that is, the caption was missing for all the images, but typically there was a problem with one of the few images of the given website. A recommended solution: a check of non-text objects, an adding of missing alternative texts. If there is a problem with objects embedded by web editors, then they should be instructed of a need to enter a text alternative directly when creating the content. The automated tools (e.g. WAVE, AChecker,) can be used for checking.

Another problematic criterion in terms of perceptibility is criterion 1.2.3 - "An alternative for time-based media or audio description of the pre-recorded video content is provided for synchronized media, except when the media is a media alternative for text and is clearly labelled as such" (Kirkpatrick et al., 2018). Most of the national tourism boards in the EU use videos for the purpose of selfpresentation that are typically shared via Youtube. However, text or audio transcripts 
to those videos are not always added. A recommended solution: a check and an adding of the text or audio transcript. It is possible to add this directly in Youtube. Furthermore, an adding of an alternative immediately when embedding new videos helps. If it is not a multimedia alternative for text, there is no need to add an alternative, but such video must be clearly labelled as the text alternative.

Figure 1. Comparison of accessibility of tourism boards websites

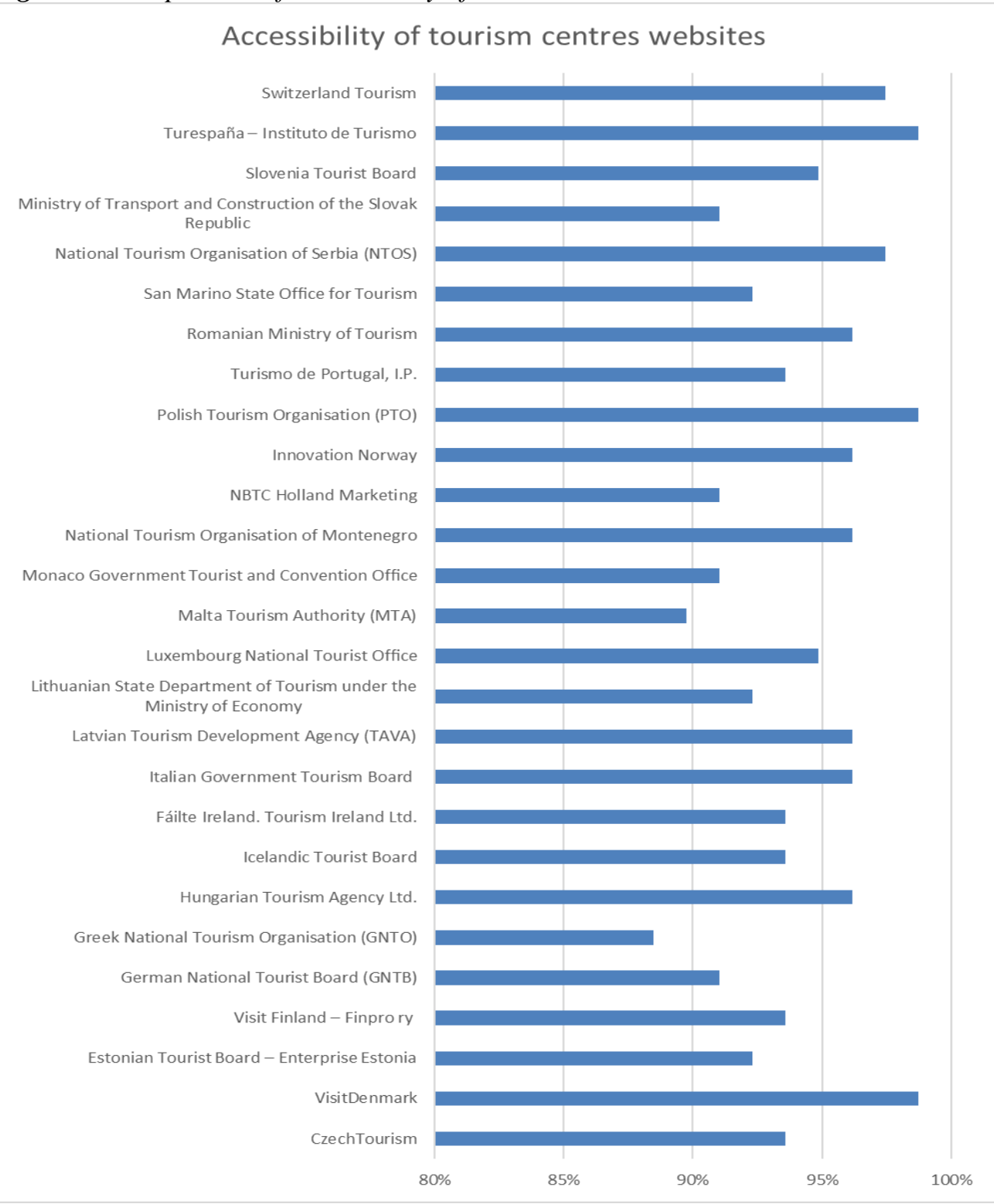

Source: Own research. 
Another principle of perceptibility where the tested websites are frequently erroneous is criterion 1.3.1 - "Information, structure, and relationships conveyed through presentation can be programmatically determined or are available in text" (Kirkpatrick et al., 2018). The problem with this criterion was identified especially for text form elements where the description was missing. Additionally, some presentations use out-dated $\langle\mathrm{b}\rangle$ or $\langle\mathrm{i}\rangle$ formatting tags instead of the structural $<$ strong $\rangle$ or $\langle$ em $\rangle$ tags. A recommended solution: replacing the $\langle b\rangle$ or $\langle i\rangle$ tags respectively for <strong $>$ or $\langle\mathrm{em}\rangle$ tags respectively and editing the content management system to use structured tags by default instead of the formatting ones. In the list of the problematic criteria there is also 1.4 .4 criterion - "Except for captions and images of text, text can be resized without assistive technology up to 200 per cent without loss of content or functionality" (Kirkpatrick et al., 2018). Unfortunately, due to relatively complex designs of some of the websites tested, by resizing the website up to $200 \%$ the design breaks up, resulting in a loss of functionality. A recommended solution: modifying the site templates to a fully replaceable design.

All previous criteria already existed in WCAG 2.0 version of 2018. The criterion 1.4.11 was added to the latest version of WCAG 2.1 in 2018 and this rule states: "The visual presentation of the following have a contrast ratio of at least 3:1 against adjacent colour(s): User Interface Components: Visual information required to identify user interface components and states, except for inactive components or where the appearance of the component is determined by the user agent and not modified by the author; Graphical Objects: Parts of graphics required to understand the content, except when a particular presentation of graphics is essential to the information being conveyed" (Kirkpatrick et al., 2018). The problem with the websites tested was the text in the image. This method is quite popular with the websites of national boards, but unfortunately it is often not very contrasting. A recommended solution: adding a background that is at least 3:1 in contrast for text used over images.

Among crucial criteria of perceptibility belongs the criterion 2.4.4 - "The purpose of each link can be determined from the link text alone or from the link text together with its programmatically determined link context, except where the purpose of the link would be ambiguous to users in general" (Kirkpatrick et al., 2018). Due to the design reasons, a graphic object is often used for the link or the form but the determined link context is not always identifiable in case the examined websites. This is also a problem with some clickable maps. A recommended solution: including the title attribute for all hypertext graphics.

The criterion 2.4.6 is brief and concise - "Headings and labels describe topic or purpose" (Kirkpatrick et al., 2018). A typical problem with the websites examined was a duplication of level 1 headings. A recommended solution: correcting the duplication of first-level $\langle$ h1 $>$ headings in the page template and modifying the content management system to prevent from duplicate first-level headings. 
The default human language of each Web page can be programmatically determined (Kirkpatrick et al., 2018). This point is quite clear. An assistive technology must be able to detect a language for each page. Unfortunately, some of the websites examined did not have the language detected in this way. A recommendation: adding the long attribute to the page, such as in the $\langle\mathrm{html}\rangle \mathrm{tag}$, can resolve the issue.

Figure 2. Identified weaknesses in accessibility of the websites tested

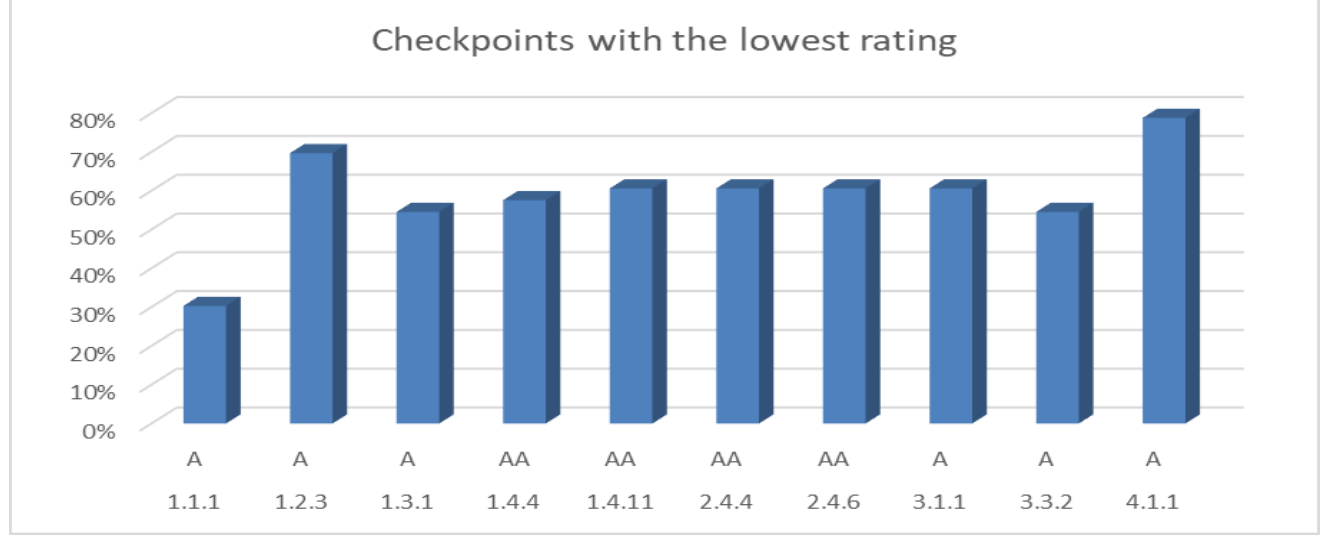

Source: Own research.

The criterion 3.3.2 (Labels or Instructions) states: "If an input error is automatically detected and suggestions for correction are known, then the suggestions are provided to the user, unless it would jeopardize the security or purpose". A typical mistake of the websites of national tourism boards in the EU was a missing label for search forms. A recommendation: appending the label attribute to all search form fields.

The criterion 4.1.1 (Parsing) states: "In content implemented using mark-up languages, elements have complete start and end tags, elements are nested according to their specifications, elements do not contain duplicate attributes, and any IDs are unique, except where the specifications allow these features." The syntax errors were diverse. A recommendation: a check using some code validator (e.g. https://validator.w3.org/); a check of the errors found and, in case the error is validated, fix it.

\section{Conclusion}

The research carried out on the websites of European national tourism boards has shown a relatively high accessibility of those websites. It is evident that all those websites are created with an emphasis on the accessibility. Nevertheless, some accessibility violations have been identified that can significantly complicate the accessibility of those websites for users using various assistive devices or other alternative hardware or software means. The most commonly identified errors include: failure to use alternative text for content-relevant images, the absence of 
text or audio transcripts for videos shared via Youtube, missing descriptions for text form elements, missing label for search form, etc.

Almost all the errors described are easy to fix without any need for complicated changes to the logic or application part of those websites. The only exception is for the criterion 1.4.4 Resize text. Due to relatively complex designs of some of the websites tested, by resizing the website the design breaks up resulting in e loss of functionality. Editing of some sites can be more complex. However, this problem can also be solved with a well-shaped responsive design.

This result can be considered very easily accessible, given both the complexity of the rules and the use of modern technologies on the websites of national tourism boards. However, it should be noted that for each boards only two pages were tested by the quantitative method and not completely the entire website. If we would thoroughly qualitatively test all the pages of the websites, the results would certainly be a little bit worse. For this reason, we also do not compare the results of individual boards in the ranking, because the results are very similar, the differences are statistically insignificant and in a more complex testing the ranking could change.

A comparative analysis of the tourist centres of European countries suggests that the web portals of Greece, Malta, Slovakia, Portugal and the Netherlands show slightly lower levels of accessibility. In contrast, the highest standards of accessibility were found for the web portals of Denmark, Poland, Latvia and Spain. However, the variability of the results was very low. The order of the individual central units cannot be considered significant. Given the complexity of the rules and the use of modern technologies on the websites of national tourism centres, the results of all centres can be considered satisfactory. Differences can be evaluated as insignificant, although the precise measurement to statistical significance is beyond scope of this paper. In order to create a reliable ranking of individual centres it would be necessary to carry out a more comprehensive research on the accessibility of multiple pages on web portals. In this study, only selected portals from 27 European countries were included, nevertheless, our sample is not identical with the current list of the EU countries.

Some research limitation of this study, which creates space for further analysis, is a methodology based exclusively on automated testing. The same limitation is apparent in the vast majority of studies published so far in professional periodicals. Automated tools enable extensive research. For this reason, it was possible to follow a wide sample of national tourist central European countries. It was possible to verify the presence of the required elements. However, qualitative research cannot be fully replaced. User testing allows you to add and extend automated tools and include personal judgment (Akgül and Vatansever, 2016; Tittelbachová and Tyslová, 2016). The involvement of organizations taking care of persons with disabilities would also be positive for the development of accessibility of web presentations in tourism. It is therefore advisable to extend dialogue between national tourist centres 
and non-profit organizations in the area of persons with disabilities. Persons with different forms of disability could be involved in subjective testing of web portals. Successful implementation of Internet accessibility would increase the possibilities of obtaining information and involving people with disabilities in international tourism.

\section{References:}

Abrhám, J., Lžičař, P. 2018. Risk management in the sustainable development: analysis of a selected key industry. Journal of Security and Sustainability Issues, 8(2), 171-180.

Abrhám, J., Wang, J. 2017. Novel trends on using ICTS in the modern tourism industry. Czech Journal of Social Sciences, Business and Economics, 6(1), 37-43.

Akgül, Y., Vatansever, K. 2016. Web Accesibility Evaluation of Government Websites for People with Disabilities in Turkey. Journal of Advanced Management Science, 4(3), 201-210.

Al Mourad, B., Kamoun, F. 2013. Accessibility evaluation of Dubai e-government websites: Findings and implications. Journal of E-Government Studies and Best Practices, $8(2), 1-15$.

Basdekis, I. Klironomos, L., Metaxas, I., Stephanidis, C. 2009. An overview of web accessibility in Greece: A comparative study 2004-2008. Universal Access in the Information Society, 9(2), 185-190.

Bondarenko, V.A., Efremenko, I.N., Larionov, V.A. 2019. Marketing Strategy for Hotel and Tourist Complex Companies. International Journal of Economics and Business Administration, 7(1), 388-394.

Brajnik, G. 2008. Beyond Conformance: The Role of Accessibility Evaluation Methods. In WISE '08 Proceedings of the 2008 international workshops on Web Information Systems Engineering, Springer Verlag, Berlin.

Brajnik, G., Yesilada, Y., Harper, S. 2010. Testability and Validity of WCAG 2.0: The Expertise Effect. In Proceedings of the 12th international ACM SIGACCESS conference on Computers and accessibility. New York, 174-181.

Caldwell, B., Cooper P., Reid, L.G., Vanderheiden, G. 2018. Web Content Accessibility Guidelines WCAG 2.0 Available at: https://www.w3.org/TR/WCAG20/.

Campbell, A. 2009. Is accessibility actually usability? Available at: http://alastairc.ac/wpcontent/uploads/2009/04/accessibility-usability-notes7.pdf.

Čech, P., Jindřichovská, I., Neubauer, J. 2019. Achieving a great reputation for corporate social responsibility: Study from the Czech hospitality industry. Scientific papers of the University of Pardubice. Series D, Faculty of Economics and Administration, 17(1), 17-28.

Čech, P., Jindrichovska, I., Neubauer, J. 2018. Corporate social responsibility in hotel industry: Empirical analysis of transitional market. International Journal of Economics \& Business Administration, 6(1), 61-89.

Connor, J.O. 2010. Is the Accessibility Audit Dead? In ICCHP'10 Proceedings of the 12th international conference on Computers helping people with special needs. Berlin. Springer-Verlag.

Craven, J., Nietzio, A. 2017. A task-based approach to assessing the accessibility of web sites. Performance Measurement and Metrics, 8(2), 98-109.

European Commission. 2015. Economic Impact and Travel Patterns of Accessible Tourism in Europe. The Publications Office of the EU, Luxembourg.

European Parliament. 2016. Directive (EU) 2016/2102 of the European Parliament and of 
The Council of 26 October 2016 on the accessibility of the websites and mobile applications of public sector bodies, Official Journal of the European Union, Brussels.

Goodwin, M., Susar, D., Nietzio, A, Snaprud, M., Jensen, C.S. 2011. Global web accessibility analysis of national government portals and ministry web sites. Journal of Information Technology and Politics, 8(1), 4167-4178.

Goryushkina, N.E., Gaifutdinova, T.V., Logvina, E.V., Redkin, A.G., Kudryavtsev, V.V., Shol, Y.N. 2019. Basic Principles of Tourist Services Market

Segmentation. International Journal of Economics and Business Administration, 7(2), 139-150.

Hong, S. Katerrattanakul, P., Joo, S. 2008. Evaluating government website accessibility: A comparative study. International Journal of Information Technology and Decision Making, 7(3), 491-515.

Isa, W., Suhami, M., Safie, N., Semsudin, S. 2011. Assessing the usability and accessibility of Malayisa E government website. American Journal of Economics and Business Administration, 3(1), 40-46.

Jindrichovska, I., Kohout M. 2016a. ERP Systems in Services: Preliminary Study from the Czech Republic. In Proceedings of the 4th International Scientific Conference IFRS: Global Rules and Local Use. Prague, Anglo-American University, 66-74.

Jindřichovska, I., Kohout, M. 2016b. Information System in Czech Hotels, Introductory Study. In Sborník z mezinárodní vědecké konference Hotelnictví, turismus a vzdělávání. Praha, Vysoká škola hotelová v Praze, 55-63.

Katrakilidis, C., Konteos, G., Sariannidis, N. and Manolidou, C. 2017. Investigation of Convergence in the Tourist Markets of Greece. European Research Studies Journal, 20(4A), 707-729.

Kirkpatrick, A., Connor, J., Campbell, A., Cooper, M. 2018. Web Content Accessibility Guidelines WCAG 2.1. Available at: https://www.w3.org/TR/WCAG21/.

Kopáčková, H., Michálek, K., Čejna, K. 2010. Accessibility and findability of local egovernment websites. Universal Access in the Information Society. Springer Verlag, Berlin.

Latif, M., Masrek, M. 2010. Accessibility evaluation on Malaysian E-government webside. Journal of e-Government Studies and Best Practices, 6(1), 1-11.

Rubáček, F. 2011. Př́istupnost webových prezentací středních škol v České republice. Media4u Magazine, 8(2), 51-55.

Rubáček, F. 2017. Přístupnost webových prezentací středních škol v České republice v letech 2010-2016. Praha. Media4u Magazine, 14(4), 8-12.

Sirotková, J., Prager, M., Abrhám, J. 2018. Accessible tourism in the Czech Republic and the European Union. Forum of Foreign Languages, Politology and International Relations. 10(1), 92-98.

Srimuk, N., Choibamroong, T. 2014. Developing Supported Health Tourism Cluster for High Quality Tourism of BRIC in Active Beach Group of Thailand. International Journal of Economics \& Business Administration, 2(1), 39-50.

Tittelbachová, Š., Tyslová, I. 2016. Destinace turismu - platforma pro spolupráci kultury a turismu. Ekonomika a management, 10(1), 1-13.

Vanderdonckt, J., Beirekdar, A., Noirhomme-Fraiture, M. 2004. Automated evaluation of web usability and accessibility by guideline review. In 4th International Conference ICWE. Munich, Germany. 